\title{
RESEARCH
}

Open Access

\section{Upregulated anti-angiogenic miR-424-5p in type 1 diabetes (model of subclinical cardiovascular disease) correlates with endothelial progenitor cells, CXCR1/2 and other parameters of vascular health}

\author{
Alice Tamara ${ }^{1,2}$, David J. Coulson ${ }^{1}$, Jevi Septyani Latief ${ }^{1,2}$, Sherin Bakhashab ${ }^{3}$ and Jolanta U. Weaver ${ }^{1,4,5^{*}}$ (D
}

\begin{abstract}
Background: In spite of clinical progress, cardiovascular disease (CVD) remains the predominant cause of mortality worldwide. Overexpression studies in animals have proven miR-424-5p to have anti-angiogenic properties. As type 1 diabetes mellitus (T1DM) without CVD displays endothelial dysfunction and reduced circulating endothelial progenitor cells (cEPCs), it offers a model of subclinical CVD. Therefore, we explored miR-424-5p, cytokines and vascular health in T1DM.

Methods: Twenty-nine well-controlled T1DM patients with no CVD and 20-matched controls were studied. Cytokines IL8, TNF-a, IL7, VEGF-C, cEPCs/CD45 ${ }^{\text {dim } C D 34} 4^{+}$CD $133^{+}$cells and ex-vivo proangiogenic cells (PACs)/ fibronectin adhesion assay (FAA) were measured. MiR-424-5p in plasma and peripheral blood mononuclear cells (PBMC) along with mRNAs in PBMC was evaluated.

Results: We found an elevation of IL7 ( $p=0.008)$, IL8 $(p=0.003)$, TNF-a $(p=0.041)$, VEGF-C $(p=0.013)$, upregulation of mRNA CXCR1 $(p=0.009)$, CXCR2 $(p<0.001)$ and reduction of CEPCs $(p<0.001)$, PACs $(p<0.001)$ and FAA $(p=$ $0.017)$ in T1DM. MiR-424-5p was upregulated in T1DM in PBMC $(p<0.001)$. MiR-424-5p was negatively correlated with CEPCs $(p=0.006)$, PACs $(p=0.005)$ and FAA $(p<0.001)$ and positively with HbA $\operatorname{Ha}_{1 c}(p<0.001)$, IL7 $(p=0.008)$, IL8 $(p=0.017)$, VEGF-C $(p=0.007), C X C R 1 \quad(p=0.02)$ and CXCR2 $(p=0.001)$. ROC curve analyses showed (1) miR-424-5p to be a biomarker for T1DM $(p<0.001)$ and $(2)$ significant upregulation of miR-424-5p, defining subclinical CVD, occurred at $\mathrm{HbA}_{1 \mathrm{c}}$ of $46.5 \mathrm{mmol} / \mathrm{mol}(p=0.002)$.

Conclusion: We validated animal research on anti-angiogenic properties of miR-424-5p in T1DM. MiR-424-5p may be a biomarker for onset of subclinical CVD at $\mathrm{HbA}_{1 c}$ of $46.5 \mathrm{mmol} / \mathrm{mol}$ (pre-diabetes). Thus, miR-424-5p has potential use for CVD monitoring whilst anti-miR-424-5p-based therapies may be used to reduce CVD morbidity/ mortality in T1DM
\end{abstract}

Keywords: MiR-424-5p, IL8, CD45 ${ }^{\operatorname{dim}} \mathrm{CD} 34^{+} \mathrm{CD} 133^{+}$, CXCR1/2, T1DM

\footnotetext{
* Correspondence: jolanta.weaver@newcastle.ac.uk

${ }^{1}$ Translational \& Clinical Research Institute, Newcastle University, Newcastle upon Tyne NE2 4HH, UK

${ }^{4}$ Department of Diabetes, Queen Elizabeth Hospital, Gateshead, Newcastle upon Tyne NE9 6SH, UK

Full list of author information is available at the end of the article
}

(c) The Author(s). 2021 Open Access This article is licensed under a Creative Commons Attribution 4.0 International License, which permits use, sharing, adaptation, distribution and reproduction in any medium or format, as long as you give appropriate credit to the original author(s) and the source, provide a link to the Creative Commons licence, and indicate if changes were made. The images or other third party material in this article are included in the article's Creative Commons licence, unless indicated otherwise in a credit line to the material. If material is not included in the article's Creative Commons licence and your intended use is not permitted by statutory regulation or exceeds the permitted use, you will need to obtain permission directly from the copyright holder. To view a copy of this licence, visit http://creativecommons.org/licenses/by/4.0/. The Creative Commons Public Domain Dedication waiver (http://creativecommons.org/publicdomain/zero/1.0/) applies to the data made available in this article, unless otherwise stated in a credit line to the data. 


\section{Background}

Cardiovascular disease (CVD) is the leading cause of mortality worldwide, accounting for $31 \%$ of global deaths in 2016 [1]. It has been long established that the development and progression of CVD could not be separated from the presence of inflammation [2]. Although similarly regarded as an inflammatory disease, diabetes mellitus also acts as one of the most important predisposing factors for CVD. In fact, the presence of type 1 diabetes mellitus (T1DM) decreases one's life expectancy by 13 years [3], predominantly due to cardiovascular events. Moreover, the risk of having CVD was reported to increase to 3.6 and 7.6 in men and women with T1DM, respectively [4]. We and others have demonstrated that T1DM without CVD has features of subclinical CVD [5-7]. It is associated with endothelial dysfunction and reduced indices of vascular health-circulating endothelial progenitor cells (cEPCs), Hills colonies, proangiogenic cells (PACs) and fibronectin adhesion assay (FAA) - known to define CVD in other patient's groups $[8,9]$. Thus, this data focuses our attention on T1DM as a model of subclinical CVD.

Recent studies discovered the differential microRNA (miR) expression in diabetic patients $[10,11]$. miRNA is a small single-stranded non-coding RNA, which acts to silence the mRNA expression in post-transcriptional level [12]. Several miRNAs have been shown to play an important role in the development of CVD [12-14]. Many pro-inflammatory miRNAs have been studied, of which miR-424-5p appeared to be a marker of plaque instability $[15,16]$.

In vitro study of miR-424 reported a significant decrease in the proliferation of pulmonary artery endothelial cells following the overexpression of miR-424 [17]. Furthermore, the upregulation of plasma miR-424-5p was correlated with higher rate of vascular events such as deep vein thrombosis and vein thromboembolism [18, 19]. MiR-424-5p was also discovered to be elevated in the plasma in relatives of T1DM [20]. The uncomplicated T1DM with good diabetic control offers a model of subclinical CVD and therefore can help to understand the early mechanisms involved in development of CVD. Understanding the role of miR-424-5p in CVD enables potential use as a biomarker and therapeutic target, to reduce burden of CVD, particularly in T1DM.

Hence, we hypothesise that miR-424-5p is upregulated in uncomplicated T1DM and associated with the increased risk of CVD.

\section{Methods}

\section{Study design}

In this cross-sectional study, we recruited 29 T1DM patients and 20 age- and gender-matched healthy subjects. The inclusion criteria for our study were T1DM patients with good glycaemic control indicated by glycated haemoglobin level $\left(\mathrm{HbA}_{1 \mathrm{c}}\right)<69 \mathrm{mmol} / \mathrm{mol}$ or $8.5 \%$ and eGFR $>45 \mathrm{ml} / \mathrm{min} / 1.73 \mathrm{~m}^{2}$ with no evidence of diabetic complications, such as CVD and active proliferative retinopathy. The sample size was calculated by power calculation as previously reported [5].

T1DM patients were recruited from Queen Elizabeth Hospital Gateshead or Royal Victoria Infirmary, Newcastle, UK. A written informed consent was obtained from each subject. This study was performed in line with the principles of the Declaration of Helsinki and was approved by the NHS Health Research Authority, NRES Committee North East-Sunderland, UK (Research Ethics Committee Reference Number 12/NE/0044).

\section{Clinical and laboratory assessment}

Peripheral blood samples were collected from all participants after an overnight fast. Plasma isolated from peripheral blood samples collected in EDTA tubes was used to assess the different levels of cytokines and angiogenic markers in the study groups. Clinical and laboratory examinations included routine laboratory tests such as full blood count, urea and electrolytes, liver function, thyroid function and $\mathrm{HbA}_{1 \mathrm{c}}$ and electrocardiogram, blood pressure, body weight, body height and body mass index.

\section{Meso Scale Discovery (MSD) assay}

Plasma samples were assayed using K15050D V-PLEX Cytokine Panel 1 human kit, K15049D V-PLEX Proinflammatory Panel 1 human kit and K15190D V-PLEX Angiogenesis Panel 1 human kit (Meso Scale Discovery, Rockville, MD) in accordance with the manufacturer's protocol. Plates were read with MSD Sector Imager 2400, and data were analysed using MSD Discovery Workbench v2.0 software.

\section{Flow cytometric evaluation of circulating endothelial progenitor cells}

The cEPCs were defined as $\mathrm{CD} 45^{\mathrm{dim}} \mathrm{CD} 34^{+} \mathrm{CD} 133^{+}$cells, and samples were analysed by flow cytometry on a $\mathrm{BD}$ FACS Canto $^{\text {тм }}$ II system (BD Bioscience, San Jose, CA, USA) as described previously [5].

\section{In vitro assays for vascular health Proangiogenic cells (PACs)}

Ficol density gradient protocol was used to isolate PBMCs. Fibronectin-coated 24-well culture plate was used to plate $1 \times 10^{6}$ PBMCs in complete endothelial basal medium (EBM-2, PromoCell, Heidelberg, Germany) supplemented with $20 \%$ fetal calf serum and growth factors-human epithelial growth factor, VEGF, human basic fibroblast growth factor, recombinant human long R3 insulin like growth factor-1, plateletderived growth factor-AA and Hep-11. Non-adherent 
cells were removed after $48 \mathrm{~h}$. Phosphate-buffered saline was used to wash the remaining adherent cells twice and cells were further incubated for $48 \mathrm{~h}$. Adherent cells were then stained on day 4 with acetylated low-density lipoprotein (Ac-LDL) and Ulex lectin (Merk, St. Louis, Missouri, US). Cells which stained positive for both Ac-LDL and Ulex lectin were classed as PACs. Fifteen random high-power fields (hpf, 200X) photographs were taken, and only dual positive cells were counted. Since PACs have been described as displaying strong neovascularization activity, this assay has been used to study neovascularization potential in studied subjects [21].

\section{Fibronectin adhesion assay}

PACs were detached gently from fibronectin coated 6-well culture plate using $5 \mathrm{mmol} / \mathrm{L}$ EDTA [22]. Once detached, these cells were washed in PBS and $1 \times 10^{5}$ cells were re-plated on fibronectin coated 48-well plate in EBM-2 (PromoCell) supplemented with 5\% fetal calf serum. The cells were incubated for $30 \mathrm{~min}$ at $37^{\circ} \mathrm{C}$ as previously described [23]. Subsequently, 48-well culture plate was vigorously washed. Remaining adherent cells were stained with Ac-LDL and Ulex lectin as mentioned above. Ten random hpf (200X) were photographed and cells which were dual positive were counted.

\section{Expressions of miRNA-424-5p and its mRNA targets Plasma samples preparation}

Platelet-free plasma was obtained through consecutive centrifugations of blood samples at $500 \times \mathrm{g}$ for $15 \mathrm{~min}$ and $13,000 \times g$ for another $5 \mathrm{~min}$. The plasma was tested for haemolysis to ensure the samples were not contaminated with cellular miRNA. An aliquot of $200 \mu \mathrm{L}$ per sample was transferred to a FluidX tube and $60 \mu \mathrm{l}$ of Lysis solution BF containing $1 \mu \mathrm{g}$ carrierRNA per $60 \mu \mathrm{l}$ Lysis Solution BF and RNA spike-in template mixture was added to the sample and mixed for $1 \mathrm{~min}$ and incubated for $7 \mathrm{~min}$ at room temperature, followed by addition of $20 \mu \mathrm{L}$ Protein Precipitation solution BF. Total RNA was extracted from the samples using miRCURY RNA isolation Kit - Biofluids, high-throughput bead-based protocol v.1 (Exiqon, Vedbaek, Denmark) in an automated 96-well format. The purified total RNA was eluted in a final volume of $50 \mu \mathrm{l}$. Plasma miRNAs were isolated from plasma samples using RNA isolation protocol optimised for plasma by QIAGEN (Exiqon Services, Denmark). The integrity of extracted RNAs were measured using 2100 Bioanalyzer (Agilent, Santa Clara, CA, USA) with the value of 9.1-10 considered as high in integrity.

\section{The sample preparation of peripheral blood mononuclear} cells

Peripheral blood mononuclear cells (PBMC) were isolated from peripheral blood using Ficol (GE Healthcare, Chicago, IL, USA). MicroRNAs and mRNAs were extracted in TRIzol (Invitrogen, Carlsbad, CA, USA) and miRNEasy Kit (QIAGEN, Hilden, Germany). The integrity of the extracted PBMC RNAs were determined using 2100 Bioanalyzer (Agilent, Santa Clara, CA, USA).

\section{Plasma miRNA real-time $P C R$}

Two microliters of RNA was reverse transcribed in $10 \mu \mathrm{l}$ reactions using the miRCURY LNATM Universal RT microRNA PCR, Polyadenylation and cDNA synthesis kit (Qiagen, Hilden, Germany). cDNA was diluted 50× and assayed in $10 \mu \mathrm{l}$ PCR reactions according to the protocol for miRCURY LNA ${ }^{\mathrm{m}}$ Universal RT microRNA PCR; each microRNA was assayed once by qPCR on the microRNA Ready-to-Use PCR using ExiLENT SYBR Green master mix. Negative controls excluding template from the reverse transcription reaction was performed and profiled like the samples. The amplification was performed in a LightCycler 480 Real-Time PCR System (Roche, Basel, Switzerland) in 384-well plates, and the amplification curves were analysed using the Roche LC software. hsa-miR-424-5p was assayed using miRCURY LNA miRNA PCR Assays with Cat number: YP00204736 (Qiagen).

Normalisation was performed based on the average of the assays detected in all samples using global mean normalisation method. For the present study, this included 7 assays hsa-miR-21-5p (TAGCTTATCAGACTGATG TTGA), hsa-miR-320a (AAAAGCTGGGTTGAGAGG GCGA), hsa-miR-23a-3p (ATCACATTGCCAGGGATT TCC), has-miR-92a-3p (TATTGCACTTGTCCCGGC CTGT), hsa-miR-223-3p (TGTCAGTTTGTCAAATAC CCCA), hsa-miR-126-3p (TCGTACCGTGAGTAATAA TGCG) and hsa-miR-15a-5p (TAGCAGCACATAATGG TTTGTG). All data was normalised to the average of assays detected in all samples (average - assay Cq).

\section{PBMCs miRNA and mRNA real-time $P C R$}

The $10 \mathrm{ng}$ of miRNAs was reversed transcribed using the miRCURY LNA RT Kit (QIAGEN, Hilden, Germany). After 100 times dilution, cDNA underwent PCR using miRCURY LNA miRNA PCR according to the manufacturer's protocol in a LightCycler 480 RealTime PCR System (Roche, Basel, Switzerland). hsa-miR424-5p was assayed using miRCURY LNA miRNA PCR Assays with Cat number: YP00204736 (Qiagen).

All data was normalised to the average of 11 assays (hsa-miR-30e-3p, Cat number: YP00204410; hsa-miR365a-3p, Cat number: YP00204622; hsa-miR-374b-5p, Cat number: YP00204608; hsa-miR-26b-3p, Cat number: 
YP00204117; hsa-miR-576-5p, Cat number: YP00206064; hsa-miR-425-3p, Cat number: YP00204038; hsa-miR-4545p, Cat number: YP00204279; hsa-miR-769-5p, Cat number: YP00204270; hsa-miR-200c-3p, Cat number: YP00204482; hsa-miR-660-5p, Cat number: YP00205911; hsa-miR-331-3p, Cat number: YP00206046; Qiagen) detected in all samples.

Reverse transcription of $150 \mathrm{ng}$ PBMC mRNAs was performed using QIAGEN RT ${ }^{2}$ First Strand Kit (QIAG EN, Hilden, Germany), yielding cDNAs, which were arrayed using RT ${ }^{2}$ Profiler PCR Array (QIAGEN, Hilden, Germany) containing CXCR1 (Cat number: PPH01040F) and CXCR2 (Cat number: PPH00608F). All Cq data was normalised to reference genes: actin- $\beta$ (Cat number PPH00073G), lactate dehydrogenase A (Cat number: PPH02047H), hypoxanthine phosphoribosyltransferase 1 (Cat number: PPH01018C), ribosomal protein, large, P0 (Cat number: PPH21138F), $\beta-2-$ microglobulin (Cat number: PPH01094E) and glyceraldehyde-3-phosphate dehydrogenase (Cat number: PPH00150F) yielding $\Delta \mathrm{Cq}$. Fold change analysis was performed using $2^{-\Delta \Delta \mathrm{Cq}}$ calculation.

\section{Prediction model: ingenuity pathway analysis (IPA) of miR- 424-5p and its mRNA targets}

The functional pathway analysis of mRNAs and miRNAmRNA relationships in relation to their implications in cardiovascular disease was conducted using ingenuity pathway analysis (IPA) software 9.0 (Ingenuity, Redwood City, CA, USA). Functional analysis using IPA offers independent target function based on (1) matching sequence of mRNA and miRNA, with weak evidence if incomplete matching, (2) correlation between the studied factors (weak evidence) and (3) direct and indirect interventional experiments (strong evidence).

The interaction site prediction between the transcripts and miR-424-5p was performed using TargetScan Human, release 7.1 (www.targetscan.org), and DianaTarBase v8, (http://carolina.imis.athena-innovation.gr/ diana_tools/web/index.php?r=tarbasev8\%2Findex) [24] databases.

\section{Statistical analysis}

Data is presented as mean \pm SD. As data was normally distributed, the difference was assessed using unpaired $t$ test. Correlation between miR-424-5p expression and other markers were measured using linear regression tests. Receiver operating characteristic (ROC) curve analysis of miR-424-5p in study participants was carried out to assess the sensitivity of miR-424-5p as a biomarker for subclinical CVD/T1DM. Moreover, ROC curve analysis of significantly elevated miR-424-5p and $\mathrm{HbA}_{1 \mathrm{c}}$ was performed to determine the cutoff value for miR-424-5p upregulation. Statistical analysis was performed using
SPSS 24.0 (SPSS $^{\text {tw }}$ Inc., Armonk, NY, USA), and the graphs were constructed using GraphPad Prism 7.0 (GraphPad software, San Diego, USA). A $p<0.05$ was considered statistically significant.

\section{Results}

Characterisation of T1DM patients and healthy controls There were 29 T1DM patients and 20 age- and gendermatched healthy controls recruited in this study. The sociodemographic characteristics and laboratory data of the studied subjects were summarised in Table 1 . The mean age of T1DM group and healthy controls were 47 and 46 respectively. T1DM group had diabetes for at least 8 years and relatively good glycaemic control, mean $\mathrm{HbA}_{1 \mathrm{c}} 57.3 \mathrm{mmol} / \mathrm{mol}(7.4 \%)$.

\section{Cytokine characteristics of study participants}

The levels of IL7 ( $2.3 \pm 0.6$ vs $1.4 \pm 0.6 ; p=0.005)$, IL8 $(4.7 \pm 1.3$ vs $2.8 \pm 0.5 ; p=0.003)$, TNF- $\alpha(1.6 \pm 0.2$ vs $1.4 \pm 0.2 ; p=0.041)$ and VEGF-C $(63.2 \pm 20.3$ vs $50.8 \pm$ 48.2; $p=0.013$ ) were detected to be significantly greater in T1DM patients compared to controls as reported previously by us [11]. The mRNA expression of $C X C R 1$ and CXCR2 were $4.3(p=0.009)$ and $2.3(p<0.001)$ foldchange higher in T1DM patients, respectively which was previously documented by us [11].

\section{Vascular health}

T1DM patients had lower angiogenic markers: cEPC/ $\mathrm{CD} 45{ }^{\mathrm{dim}} \mathrm{CD} 34{ }^{+} \mathrm{CD} 133^{+}$cells $(p<0.001)$, PACs $\quad(p<$ $0.001)$ and FAA $(p=0.017)$ compared to healthy controls (Table 1). Missing cytokine data of one healthy control was addressed and calculated as the mean of healthy control group.

\section{MiR-424-5p expression in T1DM}

A significant upregulation of miR-424-5p was detected in the PBMCs of T1DM patients with 1.8-fold increase, $p<0.001$ (Fig. 1), but not in plasma (data not shown). The correlation between miR-424-5p and systolic blood pressure was non-significant $(p=0.952)$. ROC curve analysis of miR-424-5p showed AUC $=0.966 \quad(p<0.001)$ with cutoff value of 1.49 -fold, specificity $=87.5 \%$ and sensitivity $=90.9 \%$ (Fig. 2a) to predict T1DM. We found a positive correlation between miR-424-5p in PBMC and $\mathrm{HbA}_{1 \mathrm{c}}: r^{2}=0.513, p<0.001$ (Fig. 2b). Further ROC analysis of $\mathrm{HbA}_{1 \mathrm{c}}$ in upregulated and control miR-424-5p groups yielded $\mathrm{AUC}=0.92(p=0.002)$ with $\mathrm{HbA}_{1 \mathrm{c}}$ cutoff value $46.5 \mathrm{mmol} / \mathrm{mol}(6.4 \%)$, specificity $=87.5 \%$ and sensitivity $=90.9 \%$ (Fig. 2c). 
Table 1 Clinical and metabolic characteristics of included subjects

\begin{tabular}{|c|c|c|c|}
\hline Characteristics & Healthy control group & T1DM & $p$ value \\
\hline$N$ & 20 & 29 & \\
\hline Age (years) & $46.5 \pm 11.7$ & $47.2 \pm 12.7$ & 0.8 \\
\hline Body mass index (kg/m) & $26.0 \pm 4.5$ & $28.4 \pm 6.7$ & 0.3 \\
\hline Sex (M/F) & $9 / 11$ & $14 / 15$ & - \\
\hline Duration of diabetes (years) & - & $22.4 \pm 13.9$ & - \\
\hline $\mathrm{HbA}_{1 \mathrm{c}}(\mathrm{mmol} / \mathrm{mol})$ & $35.1 \pm 2.8$ & $57.3 \pm 7.6$ & $<0.001^{* * *}$ \\
\hline $\mathrm{HbA}_{1 \mathrm{c}}(\%)$ & $5.4 \pm 0.3$ & $7.4 \pm 0.7$ & \\
\hline Fasting blood glucose (mmol/L) & $4.6 \pm 1.0$ & $9.7 \pm 3.7$ & $<0.001^{* * *}$ \\
\hline Haemoglobin (g/dL) & 14. $3 \pm 1.2$ & $14.5 \pm 1.2$ & 1.0 \\
\hline Triglycerides (mmol/L) & $1.4 \pm 0.7$ & $0.9 \pm 0.4$ & 0.145 \\
\hline Alanine aminotransferases (IU/L) & $21.3 \pm 6.1$ & $22.8 \pm 1.7$ & 0.9 \\
\hline eGFR $\left(\mathrm{ml} / \mathrm{min} / 1.73 \mathrm{~m}^{2}\right)$ & $78.09 \pm 10.05$ & $83.5 \pm 9.8$ & 0.259 \\
\hline Systolic blood pressure (mmHg) & $117.5 \pm 14.0$ & $127.5 \pm 9.4$ & $0.005^{* *}$ \\
\hline Diastolic blood pressure (mmHg) & $74.8 \pm 8.3$ & $76.8 \pm 8.8$ & 0.3 \\
\hline $\mathrm{CD} 5^{\mathrm{dim}} \mathrm{CD} 34^{+} \mathrm{CD} 133^{+} / 100$ lymphocytes (cEPCs) & $0.09 \pm 0.03$ & $0.02 \pm 0.01$ & $<0.001^{* * *}$ \\
\hline Proangiogenic cells (PACs) & $44.9 \pm 22.3$ & $14.4 \pm 7.6$ & $<0.001^{* * *}$ \\
\hline Fibronectin adhesion assay per hpf & $68.6 \pm 34.5$ & $33.9 \pm 14.7$ & $0.017^{* *}$ \\
\hline
\end{tabular}

Values are presented as means $\pm \mathrm{SD}$; unpaired $t$ test. T1DM, type 1 diabetes mellitus; $\mathrm{HbA}_{1,}$, glycated haemoglobin; CD, cluster of differentiation; $c$ EPCS, circulating endothelial progenitor cells; hpf, high power field. ${ }^{*} p<0.05$; ${ }^{* *} p<0.01$; ${ }^{* * *} p<0.001$

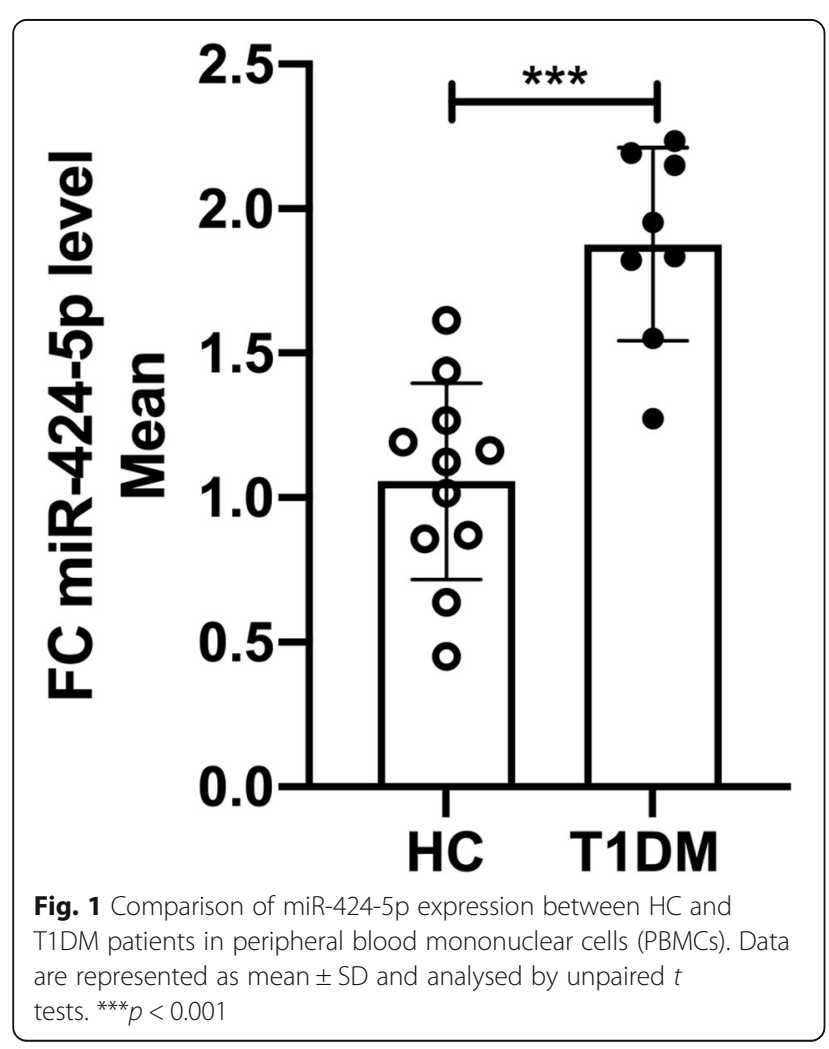

Correlations of miR-424-5p with proinflammatory cytokines and other parameters of vascular health

Linear regression analysis of miR-424-5p in PBMCs showed positive correlation with IL7 $\left(r^{2}=0.367, p=\right.$ 0.008) (Fig. 3a), IL8 $\left(r^{2}=0.306, p=0.017\right)$ (Fig. 3b), VEGF-C $\left(r^{2}=0.380, p=0.007\right)$ (Fig. 3c), CXCR1 mRNA $\left(r^{2}=0.441, p=0.002\right)$ (Fig. 3d) and CXCR2 mRNA $\left(r^{2}=\right.$ $0.564, p<0.001$ ) (Fig. 3e) whilst negatively correlated with cEPCs $\left(r^{2}=0.365, p=0.006\right)$ (Fig. 3f), PACs $\left(r^{2}=\right.$ $0.379, p=0.005$ ) (Fig. 3g) and their function in FAA $\left(r^{2}=0.485, p<0.001\right)$ (Fig. 3h). Furthermore, no statistically significant association was seen with b-FGF, IFN- $\gamma$, IL-10, IL-16, IP-10, TIMP-1, TNF- $\alpha$, E-selectin and Pselectin.

Functional pathway analysis by ingenuity pathway analysis Ingenuity pathway analysis (IPA) was used to perform the analysis of predicted mRNA targets based on miRNA sequence with or without additional supporting experimental evidence. Functional pathway analysis by IPA predicted miR-424-5p inhibiting angiogenesis and aiding mononuclear cells haematopoiesis. MiR-424-5p was strongly predicted to inhibit the mRNA expression of VEGF-A, which subsequently affected the expression of IL8, cyclooxygenase-2 (COX2) and gene encoding cyclin D1 which suppresses cell proliferation (CCND1). An 

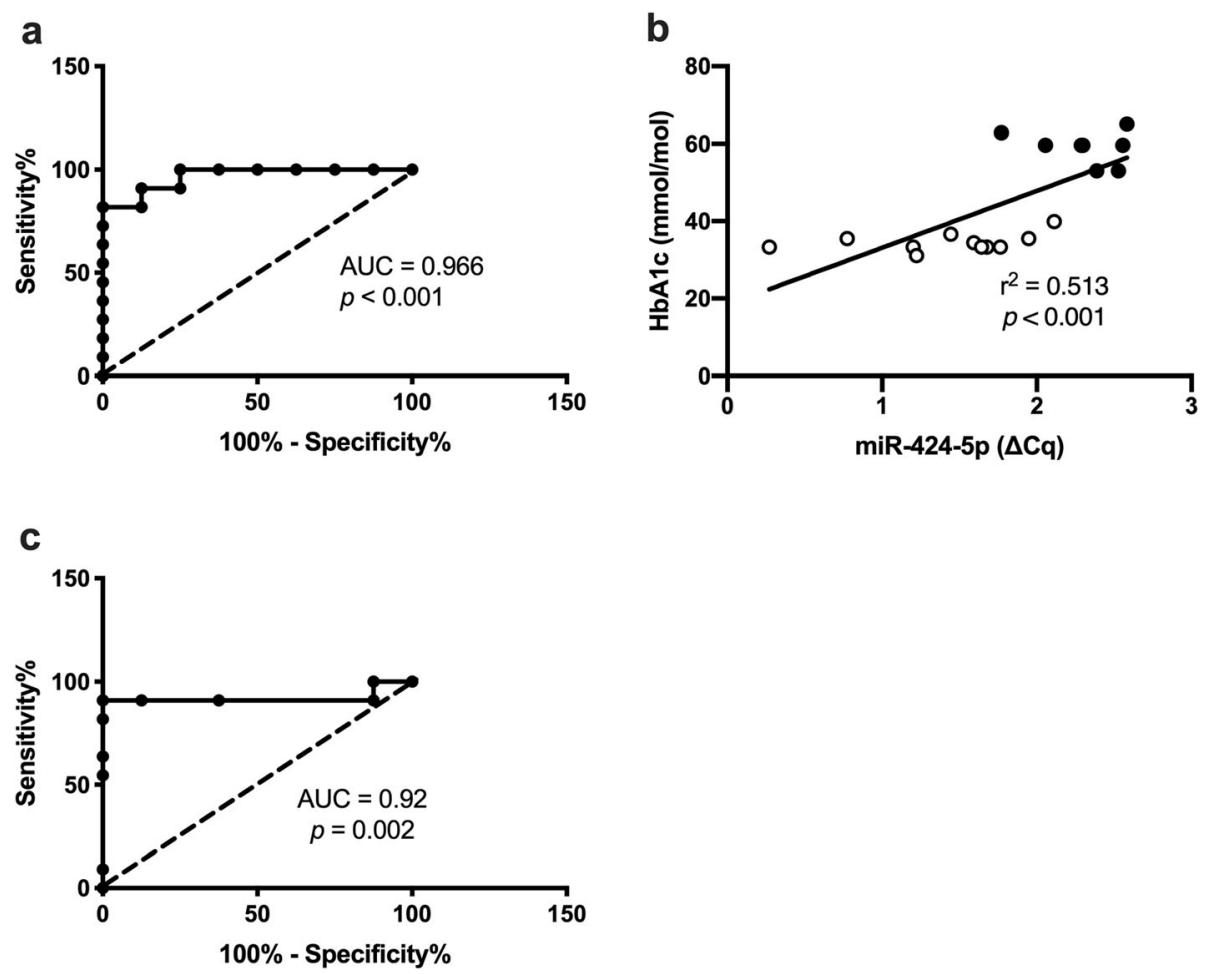

Fig. 2 a ROC curve for miR-424-5p in both study groups. b Correlation between miR-424-5p in peripheral blood mononuclear cells (PBMCs) and $\mathrm{HbA}_{1 c}\left(r^{2}=0.599, p<0.001\right)$ as a parameter to portray the glycaemic control across study groups, white dots indicated healthy control while black dots indicated T1DM. c ROC curve of $\mathrm{HbA}_{1 c}$ to define upregulated miR-424-5p expression. Statistical analysis was performed using ROC curve analysis and linear regression analysis for correlation test. $\mathrm{HbA}_{1 c}$, glycated haemoglobin

inhibitory interaction with a weak evidence level was predicted between miR-424-5p and VEGF-C, inhibiting angiogenesis. The overexpression of miR-424-5p was predicted to supress the expression of CD40 mRNA, a crucial factor for antigen presenting cell, which works through IL8 to activate CXCR1 and CXCR2. CD40 was also speculated to activate COX2 to inhibit angiogenesis (Fig. 4).

\section{Discussion}

In this study, well-controlled T1DM patients without CVD were considered as a model of subclinical CVD. Patients had diabetes sufficiently long enough to be suitable for studying early stages of CVD. Our data are in concordance with previous studies, showing an upregulation of proinflammatory cytokines IL7, IL8 and TNF- $\alpha$ along with the reduction of vascular health cEPCs, PACs and FAA in T1DM or diabetic animal models $[7,11$, 25-28]. Others studied the upregulation of miR-424-5p in plasma in T1DM only and without further analysis [20]. We took our observation further and correlated our findings with indices of vascular health such as cEPCs (angiogenesis), fibronectin adhesion assay (cell adhesion) and proangiogenic cells (neovascularization potential). We are the first group to show that miR-424- 5p was indeed upregulated in PBMCs of T1DM patients and this upregulation was associated negatively with indices of vascular health. Data was analysed as correlation between miR and other parameters.

\section{Confirmation of T1DM and CVD as inflammatory diseases}

An upregulation of IL7, a lymphoid haematopoietic growth factor, recorded by us [11], has been shown to be associated with autoimmune diseases, such as multiple sclerosis and diabetes [29]. IL7 aided the expansion of autoreactive CD4 and CD8 T cells in the development of T1DM [29].

Moreover, significant elevations of serum TNF- $\alpha$ and IL8 in T1DM patients were observed in this study as described previously by us [11], confirming preceding research in T1DM [7, 25]. As a proinflammatory cytokine, TNF- $\alpha$ induced the secretion of IL8 to promote the inflammatory pathway [30]. IL8, in turn, recruited neutrophils and monocytes to the inflamed tissues by the activation of its receptors, CXCR1 and CXCR2 [31]. Supported by the upregulated mRNA of CXCR1 and CXCR2 in T1DM patients, this study suggests the presence of continuous induction of inflammatory signal, underlining the pathogenesis of most inflammatory diseases, such as T1DM and CVD [25, 32]. 

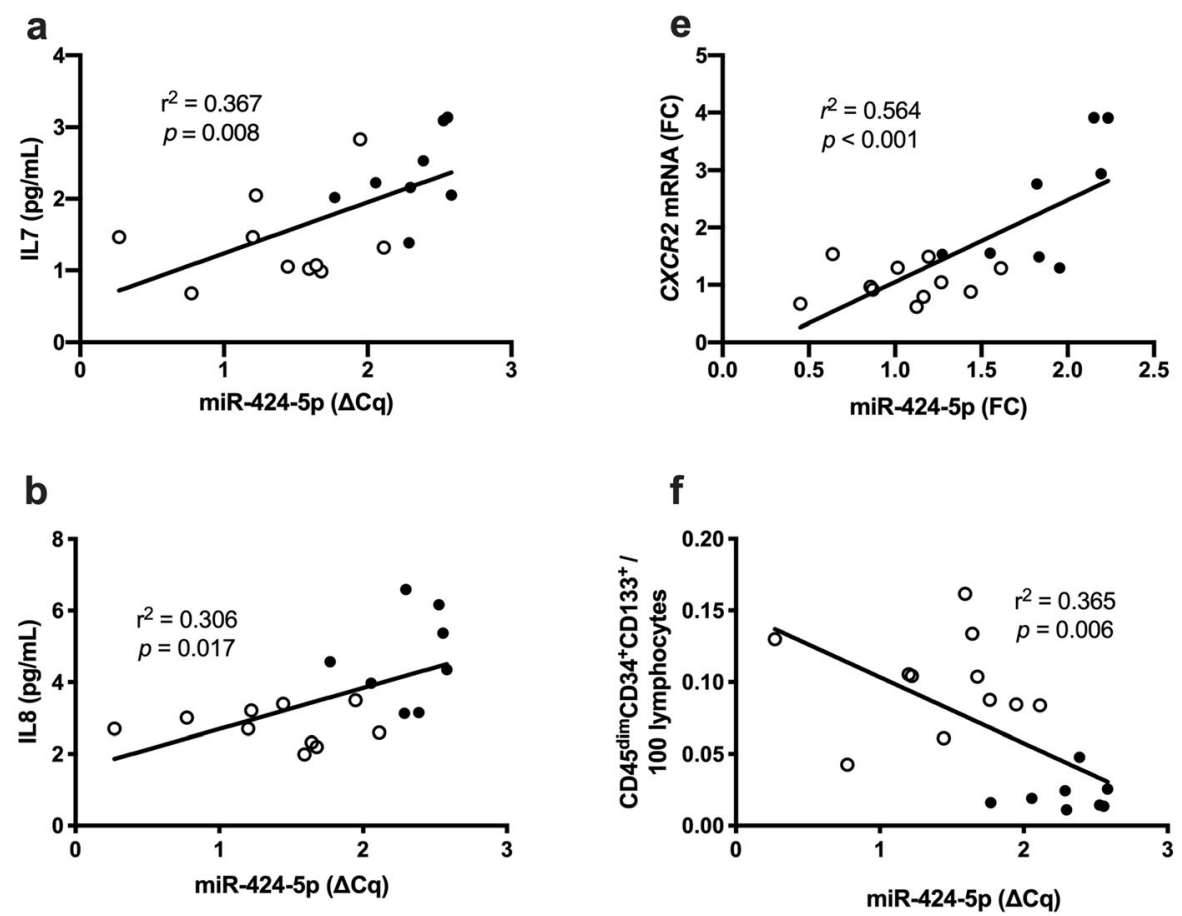

C
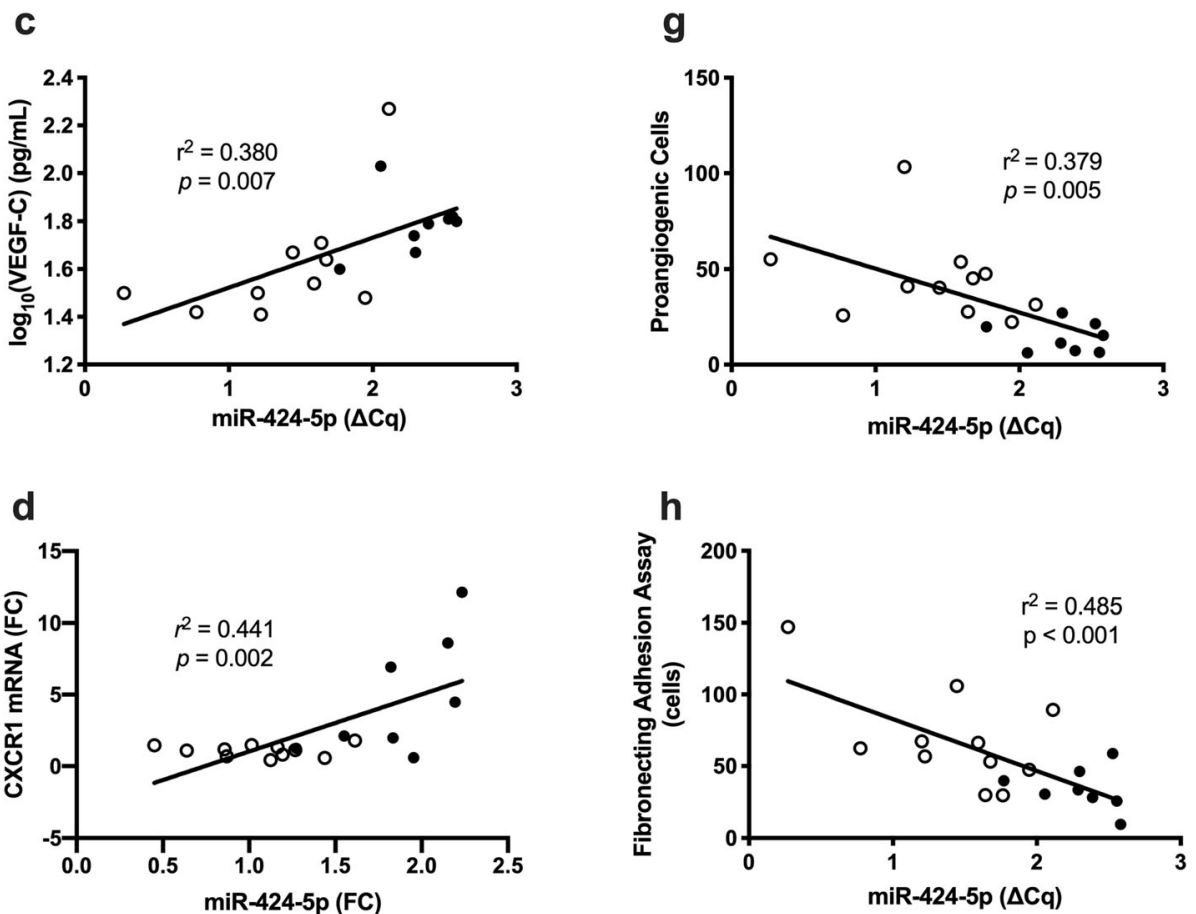

Fig. 3 Correlation between miR-424-5p in peripheral blood mononuclear cells (PMBC and inflammatory cytokines $\mathbf{a} \| \mathrm{L} 7\left(r^{2}=0.442, p=0.003\right), \mathbf{b}$ IL8 $\left(r^{2}=0.385, p=0.006\right)$, c VEGF-C $\left(r^{2}=0.368, p=0.008\right)$, $\mathbf{d}$ CXCR1 mRNA in PBMC $\left(r^{2}=0.441, p=0.002\right)$ and e PBMC CXCR2 mRNA $\left(r^{2}=0.564\right.$, $p<0.001)$ and angiogenic markers: $\mathbf{f} C D 45^{\mathrm{dim}} \mathrm{CD} 34^{+} \mathrm{CD} 133^{+}\left(r^{2}=0.43, p=0.002\right)$, $\mathbf{g}$ proangiogenic cells $\left(r^{2}=0.418, p=0.003\right)$, and $\mathbf{h}$ fibronectin adhesion assay $\left(r^{2}=0.396, p=0.004\right)$, across study groups in the plasma. Statistical analysis was carried out using linear regression analysis. IL, interleukin; VEGF, vascular endothelial growth factor; CD, cluster of differentiation. White dots indicated healthy control while black dots indicated T1DM 
Path Designer figure in paper plus INSR

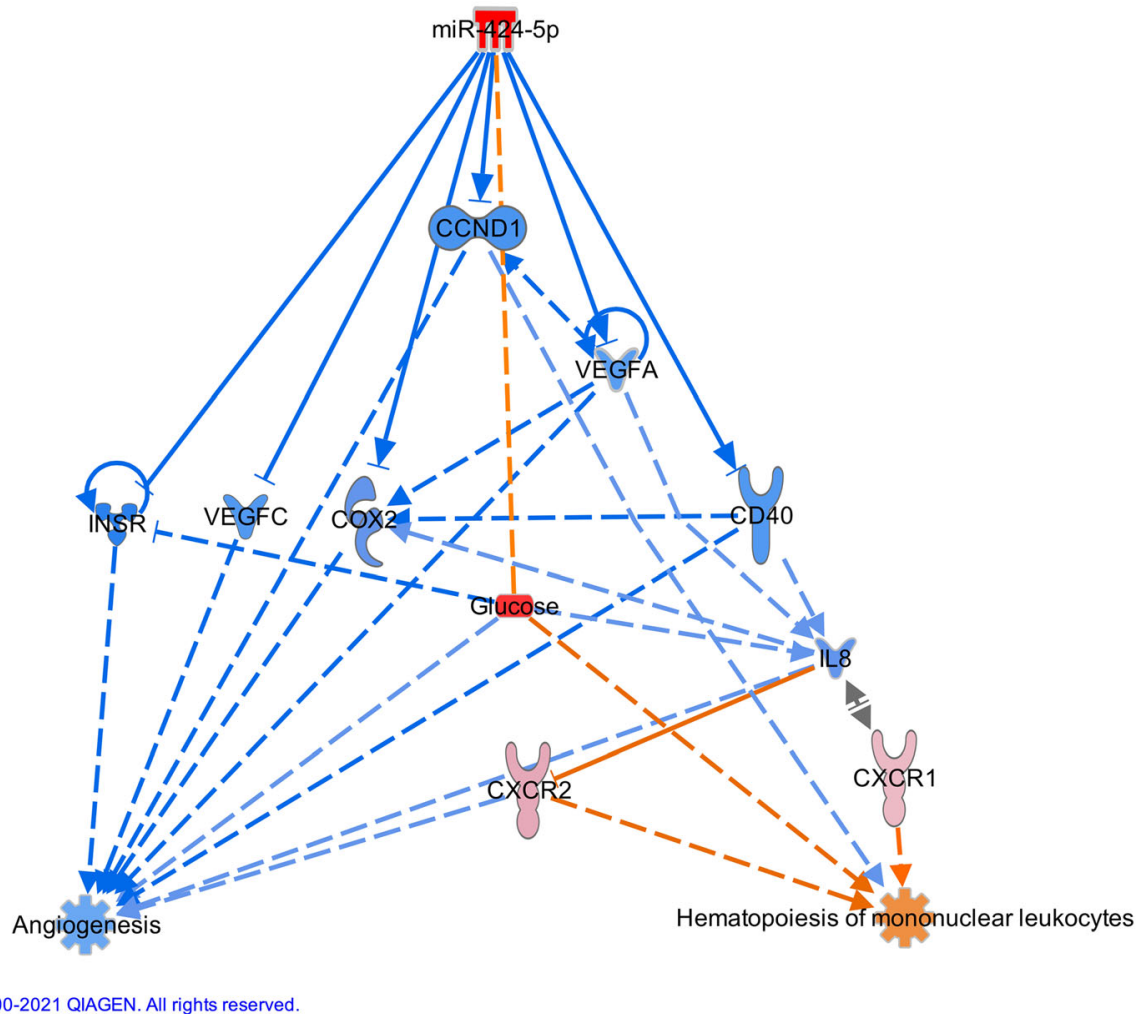

Fig. 4 Ingenuity pathway analysis (IPA) prediction network of miR-424-5p using our data and its mRNA targets and cytokines supporting its involvement in cardiovascular disease. Three pathways were considered as relevant in this study: angiogenesis, haematopoiesis of monunuclear cells and insulin receptor signalling. CD, cluster of differentiation; COX2, cyclooxygenase-2; VEGF, vascular endothelial growth factor; CCND1, gene encoding cyclin D1; IL, interleukin, CXCR, chemokine receptors

Patients included in our study had no evidence of CVD, but the presence of elevated pro-inflammatory cytokines is in line with the predisposition to asymptomatic CVD in these patients. Hence, our findings further confirm the inflammatory nature of T1DM and its contribution to increase the risk of developing CVD.

\section{MiR-424-5p association with vascular health}

T1DM has been closely related with macrovascular complications such as myocardial infarction and defective vascular capacity, including delayed wound healing [3, 4]. The reduction in vascular health of T1DM patients, revealed by the diminished cEPCs, PACs and FAA, was previously reported by us [5]. Circulating EPCs, fraction of PBMCs, are cells which play an important role in maintaining endothelial integrity, aiding neovascularisation and regeneration of endothelial cells and predicting future CVD events $[9,33]$. The inverse correlation with cEPCs may confirm animal experiments that miR-424$5 p$ is antiangiogenic. Further evidence of antiangiogenic effect of miR-424 may come from the inverse correlation with in vitro vascular function such FAA or PACs demonstrating adhesion or neovascularization properties of cells involved in vascular health.

The $r^{2}$ value varied for different linear regression models (Fig. 2b and Fig. 3) from 0.5 to 0.3 . The possible explanation is that, as the number of data points was the same in all linear regression models, moderate $r^{2}$ may be a reflection that less variation of a dependent variable is explained by the independent variable.

The studies proving causal relationship of miRs in vascular health in patients are still beyond our reach as mechanist experiments in patients are still not possible. However, both circulating EPCs and attached PACs originate from PBMCs; thus, it may well be possible that miR-424-5p are also overexpressed in those cells. Further studies are thus required to answer those important questions. The correlations found by us may confirm indirectly the results from animals' research, in which miR-424 overexpression caused a significant decrease in proliferation of pulmonary artery endothelial cells [17]. We have shown inverse relation of miR-424-5p with cEPCs, PACs and FAA. In the hindlimb ischemia model, PACs cultured from BPBMCs not only secreted several 
cytokines such as VEGF and IL-8 (miR-424-5p gene targets (Fig. 4) involved in vascular health but also induced well-organised perfused vessels when transplanted which showed neovascularization activity [21].

Hence, considering the nature of miR-424-5p which is deleterious to vascular health when being overexpressed $[18,19]$, the upregulation of miR-424-5p in T1DM patients may contribute to the increased risk of CVD in T1DM. Recent studies in unstable atherosclerotic plaque from patients with peripheral arterial disease identified highly expressed Notch ligand Delta-like 4 (Dll4) and miR-424-5p, complex associated with disease progression [16].

\section{MiR-424-5p and cytokines}

Our results showed direct relation between miR-424-5p in PBMCs and concentration of circulating IL-8, IL-7 and VEGF-C cytokines. The relationship between miR424-5p expression and cytokines has been demonstrated in previous studies.

In cancer, dysregulation of suppressor of cytokines signalling (SOCS) protein expression was common. It was reported that miR-424-5p expression was essential in mediating IL-8/STAT5/SOCS2 pathway in inducing cell migration and cellular invasiveness in oral squamous cell carcinoma. IL-8 displayed its function by inducing the expression of miR-424-5p and hence modulating SOCS2/STAT5 signalling [34]. Hence, the upregulation of miR-424-5p in T1DM may be caused by the chronic IL-8 elevation. However, this requires confirmation in non-cancerous tissues.

We found a positive linear relation between miR-4245p and mRNA CXCR1 and mRNA CXCR2 and between miR-424-5p and IL-8 cytokine. Moreover, the activation of CXCR1/2 chemokine receptors by IL8, expressed in granulocytes, monocytes and microphages led to trafficking cells to inflammatory sites including arteriosclerotic plaques [35, 36]. Our group is first to report the correlation of miR-424-5p with mRNA CXCR1 and CXCR2 in PBMCs whilst circulating IL-8 was also elevated. This finding may point toward atherogenic action of elevated miR-424-5p, mRNA CXCR1 and CXCR2, especially as IL-8 cytokine has been found to be mitogenic and chemotactic for smooth muscle cells [37].

We have shown a direct linear relationship between miR-424-5p and IL-7 concentrations. The elevated levels of IL-7 have been shown in patients with acute coronary syndrome. Furthermore, IL-7 enhanced the expression of inflammatory chemokines in monocytes and PBMCs in these patients [38]. Others suggested IL-7 to have predictive value for mortality from cardiogenic shock following myocardial infarction [39]. Cytokine IL-7 was involved in the inflammatory pathway consisting of monocyte trafficking into atherosclerotic plaques [40]. In addition, in laboratory experiments, IL-7 increased cell adhesion molecules and monocyte chemoattractant in endothelial cells and promoted monocyte adhesion and trafficking of macrophages into aortas of $\mathrm{ApoE}^{-/-}$mice whilst IL-7 receptor blockade reversed that process [41]. Integrative analysis of miRNA-mRNA network in highattitude retinopathy predicted IL-7 receptor to be a target for both miR-369-3p and miR-424-5p [42]. However, retinopathy is a unique model and reflects small vessel disease; thus, further studies are necessary on IL-7R and miR-424-5p in large vessel disease (CVD).

\section{PBMC miR-424-5p expression in T1DM patient}

The strength of our study lies in studying in parallel the expression of miR-424-5p in both PBMC and plasma. We have shown for the first time that the upregulation of miR-424-5p in PBMC, but not in plasma, of T1DM patients (Fig. 1).

Although the upregulation of serum miR-424-5p in DM patients has been recorded in previous research [20], it is crucial to ensure the purity of cell-free-plasma before analysing the plasma samples using RT-PCR, which we have employed in this study. This is particularly important since miRNA analysis in platelet-freeplasma and standard plasma was reported to yield different results [43]. Thus, discrepancy between abovementioned studies may be related to pre-analytical methodology used.

\section{MiR-424-5p and T1DM}

We are the first group to report in T1DM patients raised miR-424-5p in PBMCs. Our results are supported by the evidence from recently published study in rodent model of T1DM. Specifically, in Wistar male rats induced by streptozotocin (model of T1DM), hsa-miR-424-5p mimic plasmid and hsa-mir-424-5p inhibitor plasmid were designed and injected. The results of that study showed that hsa-miR-424-5p mimic group had the highest expression of hsa-miR-424-5p in lymphocytes and hsa-miR-424-5p linked to programmed cell death 1 signalling (PD-1), which stimulated the immune response through the mechanistic target of rapamycin kinase signalling pathway (mTORC) and therefore participated in the pathogenesis of T1DM [44].

Furthermore, another study reported the upregulated miR-424-5p as a biomarker for positive autoantibody status, in relatives of T1DM patients, who subsequently developed type 1 diabetes during the follow-up [20]. Recent study showed higher urinary exosomal miR-424 expression in T1DM in children than in healthy controls [45]. Our study assessed the ROC curve of miR-424-5p in T1DM and healthy controls. We obtained an AUC of $0.966(p<0.001)$, and data showed that miR-424-5p is a strong biomarker for T1DM with $90.9 \%$ sensitivity and 


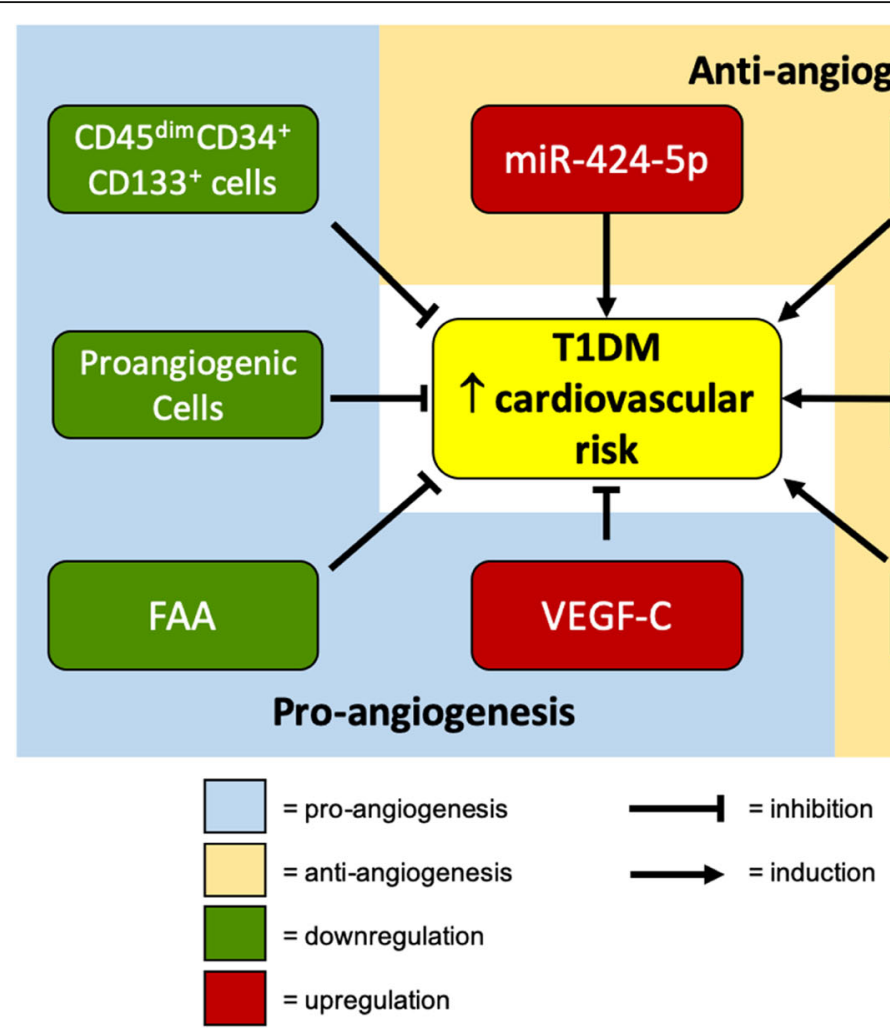

Fig. 5 Summary of our study results in T1DM. The upregulated miR-424-5p, cytokines (VEGF, vascular endothelial growth factor; IL, interleukin) or their receptors (CXCR, chemokine receptor) contributed to increased cardiovascular risks in T1DM patients whilst vascular health—fibronectin adhesion assay(FAA), proangiogenic cells and $\mathrm{CD} 45^{\mathrm{dim}} \mathrm{CD} 34^{+} 133^{+}$cells - was reduced in the same patients with T1DM, type 1 diabetes mellitus, thus displaying impaired vascular repair

$87.5 \%$ specificity (Fig. 2a). This is consistent with a positive association between glycaemic control, miR-424-5p level and prediction on IPA pathway analysis. The most important proof of our finding are the intervention studies, in which the administration of high glucose concentration in either human mesenchymal stem cells or mouse models, led to miR-424-5p rise, confirming that miR-424-5p is caused by hyperglycaemic state [46, 47].

Although our analysis points toward miR-424-5p being a biomarker for T1DM, there may be an alternative conclusion to our finding as one has other means of diagnosing T1DM including HbA1c. We postulated that miR-424-5p is a biomarker for early subclinical CVD and the difference in miR-424-5p expression could be attributed to the presence or absence of hyperglycaemia.

Consequently, we tested the above-mentioned hypothesis by assessing the cutoff value of $\mathrm{HbA}_{1 \mathrm{c}}$, for which miR-424-5p was upregulated to determine if miR-424-5p could itself predict CVD in our cohort of subjects. It is of interest that the value of $\mathrm{HbA}_{1 \mathrm{c}} 46.5 \mathrm{mmol} / \mathrm{mol}$ (6.4\%) achieved from ROC curve analysis also signified the turning point for development of diabetes and commonly phrased as prediabetes state [48]. To validate our original finding, the values of $\mathrm{HbA}_{1 \mathrm{c}}$ used to define the diabetes state are equally defined by the development of microvascular complication [48, 49]. In our study of well-characterised controls and diabetic patients, we found independently by using miR-424-5p, the biochemical set point for diabetic complications. This cutoff defined an increased CVD risk and appeared to coincide within the pre-diabetes range $(42-47 \mathrm{mmol} / \mathrm{mol}$ or 6.0 6.49\%). Despite the small study size, this independent analysis can be used to confirm that miR-424-5p is a biomarker for the beginning of CVD. Others also reported miR-424-5p to be a biological marker of intracranial aneurism [50] or predictor of risk of fatal myocardial infarction whilst combined with Framingham score [51].

Thus, this finding has practical application, as reliable diagnosis of subclinical CVD is notoriously difficult without using invasive methods. Therefore, miR-424-5p can act as either biomarker of CVD onset or CVD progression or both. The upregulation of 
miR-424-5p emphasises the increasing cardiovascular risk with the presence of T1DM even in the absence of clinical CVD.

\section{Prediction model: functional pathway analysis of miR-} 424-5 $p$ in relation to cardiovascular function

IPA predicted miR-424-5p to regulate angiogenesis and haematopoiesis of mononuclear leukocytes (Fig. 4). The upregulation of miR-424-5p was predicted to inhibit mRNA expression of CD40, VEGF-A, VEGF-C and COX2. These interactions result in an activation of CXCR1 and CXCR2 along with subsequent protein inhibitions (cyclin D1, IL8) to halt angiogenesis and activate mononuclear leukopoiesis. This prediction is in line with our mRNA analysis, which showed an upregulation of CXCR1 and CXCR2 mRNA concentrations following an upregulation of miR-424-5p in T1DM patients (Fig. 3d, e).

The predicted interaction of upregulated miR-424-5p to downregulate angiogenic growth factor, VEGF-C, was based on incomplete matching sequence (weak evidence). This is also in line with the previous nondiabetic mice study, showing the upregulated miR-424 to reduce VEGF expression in endothelial cells [52]. However, this prediction does not take into account the influence of diabetes on VEGF regulation.
Therefore, it is not surprising that this part of the network prediction contradicts our data which shows an upregulation in VEGF-C and no significant change in of VEGF-A and VEGF-D that we have studied (data not shown). Furthermore, contrary to the IPA prediction, our findings are also supported by a positive correlation between miR-424-5p and VEGF-C concentration. Moreover, if endothelial growth factors such as VEGF-A, VEGF-C and VEGF-D would be upregulated, this would have led to an elevation in cEPCs and PACs, which was not the case in our participants. Hence, we speculate that the elevation in VEGF-C is more likely to be compensatory mechanism in T1DM patients to induce angiogenesis and it is regulated by different mechanism, which we have not studied here.

Our interpretation of VEGFs findings is in line with the previous research showing VEGFs elevation in diabetes $[27,28]$ and supported by our own in vitro study [26]. In diabetes, the impairment in angiogenesis, despite of elevated VEGFs, is due to the downregulation of VEGF receptors (VEGFR) and impairment in VEGFVEGFR signalling. This leads to upregulation of the upstream signal, VEGFs, as shown by others [26-28]. The summary of our research is graphically represented in Fig. 5.

The limitation of this study includes the use of cross-sectional data. Hence, we recommend a future

Table 2 Predicted consequential pairing of target region in the transcript and miR-424-5p

\begin{tabular}{|c|c|c|c|c|c|}
\hline $\begin{array}{l}\text { Target } \\
\text { gene }\end{array}$ & $\begin{array}{l}\text { Representative } \\
\text { transcript }\end{array}$ & Gene name & $\begin{array}{l}\text { Transcript } \\
\text { position }\end{array}$ & $\begin{array}{l}\text { Predicted consequential pairing of target region } \\
\text { Transcript (top) and miRNA (bottom) }\end{array}$ & $\begin{array}{l}\text { Site } \\
\text { type }\end{array}$ \\
\hline \multirow[t]{2}{*}{ CCND1 } & ENST00000227507.2 & Cyclin D1 & 1961-1967 3'UTR & $\begin{array}{l}\text { (Transcript) } \\
\text { 5' CCAUUUUCUUAUUGCGCUGCUAC 3' } \\
\text { (miRNA) } \\
\text { 3' AAGUUUUGUACUUAACGACGAC 5' }\end{array}$ & 7mer-A1 \\
\hline & & & 2033-2040 3'UTR & $\begin{array}{l}\text { (Transcript) } \\
\text { 5' CUCUUUCACAUUGUUUGCUGCUA 3' } \\
\text { (miRNA) } \\
\text { 3' AAGUUUUGUACUUAACGACGAC 5' }\end{array}$ & 8 mer \\
\hline VEGFA & ENST00000372067.3 & Vascular endothelial growth factor A & 276-283 3'UTR & $\begin{array}{l}\text { (Transcript) } \\
\text { 5'CCAUUUUAUUUUUCUUGCUGCUA 3' (miRNA) } \\
3^{\prime} \text { AAGUUUUUGUACUUAACGACGAC 5' }\end{array}$ & 8mer \\
\hline CD40 & ENSG00000101017 & $\begin{array}{l}\text { CD40, TNF receptor superfamily member } \\
5\end{array}$ & $\begin{array}{l}61-71 \\
3^{\prime} U T R\end{array}$ & $\begin{array}{l}\text { (Transcript) } \\
\text { 5' CUUCCUGGCUCCAACACUGCUGCUC 3' } \\
\text { (miRNA) } \\
3^{\prime} \text { AAGUUUUGUACUUAACGACGAC 5' }\end{array}$ & 7mer \\
\hline $\operatorname{cox} 2$ & $\begin{array}{l}\text { ENSG00000073756 } \\
\text { (PTGS2) }\end{array}$ & Cyclooxygenase-2 & $\begin{array}{l}165-179 \\
3^{\prime} U T R\end{array}$ & 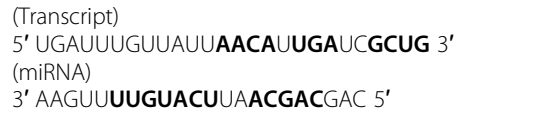 & 6 mer \\
\hline \multirow[t]{2}{*}{ INSR } & ENSG00000171105 & Insulin receptor & $\begin{array}{l}4218-4241 \\
3^{\prime} U T R\end{array}$ & $\begin{array}{l}\text { Transcript) } \\
\text { 5'UCCUCAAAUUGACCAAUAGCUGCUGC 3' } \\
\text { (miRNA) } \\
\text { 3' AAGUUU UGUACUUAACGACGAC 5' }\end{array}$ & 7mer \\
\hline & & & $\begin{array}{l}\text { 3844-3871 } \\
\text { 3'UTR }\end{array}$ & 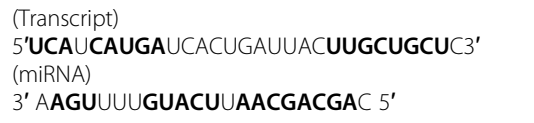 & 8mer \\
\hline
\end{tabular}


longitudinal study to investigate the role of miR-424$5 \mathrm{p}$ in progression of CVD risk in T1DM patients.

\section{Contribution/causation}

MiR-424-5p has effect on 32 pathways (mirPath-v3) of which many are interrelated. Since our clinical study relies on comparisons and correlations, the contribution or causality may be drawn from miR-424-5p target genes binding site as listed in Table 2. MiR-424-5p has binding sites in 5 target genes of interest. The highest number of binding sites was found among insulin receptor signalling pathway. Thus, it appears that miR-424-5p has causal role in glucose metabolism via insulin receptor pathway. The next causal effect of miR-424-5p is on CCND1 gene, which belongs to the highly conserved cyclin family involved in smooth muscle proliferation (VSMCs). The further causal effect is via CD40, gene coding for the TNF-receptor superfamily. This receptor has been found to be essential in mediating a wide variety of immune and inflammatory responses. The other causal role of miR-424-5p is on an important target gene (COX2), precursor for prostacyclin synthesis, which is involved in inflammation. Last but not the least was the causal effect of miR-424-5p in our model on VEGFA, inherently involved in angiogenesis [53].

Although reporting correlations from patients does not provide definitive answers to the mechanism involved, we believe it is pivotal, in exploring new research avenues, as it is generated by clinical findings and therefore may shorten the time from the bench to bedside.

\section{Conclusions}

Taken together, this study in patients with T1DM validated animal research. Our data indicates that miR-424$5 p$ may be used as a sensitive biomarker for subclinical cardiovascular disease and has potential as a therapeutic or monitoring target in CVD. The study conclusions are drawn from correlations found and supported regarding contribution/causation by binding sites for miR-424-5p in insulin receptor pathways, CD40, CCND1, VEGFA and $\mathrm{COX} 2$ genes.

\section{Abbreviations \\ CCND1: Gene encoding cyclin D1; CD: Cluster of differentiation: CEPC: Circulating endothelial progenitor cells; COX2: Cyclooxygenase-2; CVD: Cardiovascular disease; CXXR: Chemokine receptor; FAA: Fibronectin adhesion assay; $\mathrm{HbA}_{1}$ : Glycated haemoglobin; IL: Interleukin; IPA: Ingenuity pathway analysis; miR: microRNA; PAC: Proangiogenic cell; PBMC: Peripheral blood mononuclear cell; ROC: Receiver operating characteristic; T1DM: Type 1 diabetes mellitus; VEGF: Vascular endothelial growth factor; VEGFR: VEGF receptors}

\section{Acknowledgements}

We thank all subjects for their participation in this research and F. Ahmed for his help with the MERIT study. We also express our gratitude to the Clinical Research Facility and its staff at Royal Victoria Infirmary, Newcastle, for their provision in terms of the resources and facilities to conduct this study. This work was supported by Diabetes Research and Wellness Foundation UK [open funding 2011] and Diabetes Research Fund at Queen Elizabeth Hospital, Gateshead, UK

\section{Code availability}

Not applicable.

\section{Authors' contributions}

AT: writing of the manuscript, analysis and interpretation of the data. DJC, JSL: analysis and interpretation of the data. SB: laboratory experiments interpretation of the data and drafting of the manuscript. JUW: conception and design of the study, securing the funding, recruitment of patients, laboratory experiments, acquisition of data, analysis and interpretation of the data, writing of the manuscript and writing supervision. JUW is the guarantor of this work and, hence, had full access to all the data in the study and took responsibility for the integrity of the data and the accuracy of the data analysis. All authors read and approved the final manuscript.

\section{Funding}

This work was supported by Diabetes Research and Wellness Foundation UK [open funding 2011] and Diabetes Research Fund at Queen Elizabeth Hospital, Gateshead, UK.

\section{Availability of data and materials}

The datasets used and/or analysed during the current study are available from the corresponding author on reasonable request.

\section{Declarations}

Ethics approval and consent to participate

This study was approved by the NHS Health Research Authority, NRES Committee North East-Sunderland, UK (Research Ethics Committee Reference Number 12/NE/0044). A written informed consent was obtained from each subject in the study.

\section{Consent for publication}

Not applicable.

\section{Competing interests}

The authors declare no conflict of interests.

\section{Author details}

${ }^{1}$ Translational \& Clinical Research Institute, Newcastle University, Newcastle upon Tyne NE2 4HH, UK. ²Faculty of Medicine, Universitas Indonesia, Jakarta 10430, Indonesia. ${ }^{3}$ Biochemistry Department, Faculty of Science, King Abdulaziz University, Jeddah 80218, Saudi Arabia. ${ }^{4}$ Department of Diabetes, Queen Elizabeth Hospital, Gateshead, Newcastle upon Tyne NE9 6SH, UK. ${ }^{5}$ Vascular Biology and Medicine Theme, Newcastle University, Newcastle upon Tyne NE2 4HH, UK.

Received: 1 February 2021 Accepted: 7 April 2021

Published online: 14 May 2021

\section{References}

1. Organization WH. Noncommunicable diseases country profiles 2018. 2018

2. Ruparelia N, Chai JT, Fisher EA, Choudhury RP. Inflammatory processes in cardiovascular disease: a route to targeted therapies. Nat Rev Cardiol. 2017; 14(5):314. https://doi.org/10.1038/nrcardio.2017.33.

3. Livingstone SJ, Levin D, Looker HC, Lindsay RS, Wild SH, Joss N, et al. Estimated life expectancy in a Scottish cohort with type 1 diabetes, 20082010. JAMA. 2015;313(1):37-44. https://doi.org/10.1001/jama.2014.16425.

4. de Ferranti SD, de Boer $1 \mathrm{H}$, Fonseca V, Fox CS, Golden SH, Lavie CJ, et al. Type 1 diabetes mellitus and cardiovascular disease: a scientific statement from the American Heart Association and American Diabetes Association. Diabetes Care. 2014;37(10):2843-63. https://doi.org/10.2337/dc14-1720.

5. Ahmed FW, Rider R, Glanville M, Narayanan K, Razvi S, Weaver JU. Metformin improves circulating endothelial cells and endothelial progenitor cells in type 1 diabetes: MERIT study. Cardiovasc Diabetol. 2016;15(1):116. https://doi.org/10.1186/s12933-016-0413-6.

6. Sibal L, Aldibbiat A, Agarwal SC, Mitchell G, Oates C, Razvi S, et al. Circulating endothelial progenitor cells, endothelial function, carotid intimamedia thickness and circulating markers of endothelial dysfunction in 
people with type 1 diabetes without macrovascular disease or microalbuminuria. Diabetologia. 2009;52(8):1464-73. https://doi.org/10.1007/ s00125-009-1401-0

7. West DJ, Campbell MD, Gonzalez JT, Walker M, Stevenson EJ, Ahmed $F W$, et al. The inflammation, vascular repair and injury responses to exercise in fit males with and without type 1 diabetes: an observational study. Cardiovasc Diabetol. 2015;14(1):71. https://doi.org/10.1186/s12933015-0235-y.

8. Hill JM, Zalos G, Halcox JP, Schenke WH, Waclawiw MA, Quyyumi AA, et al. Circulating endothelial progenitor cells, vascular function, and cardiovascular risk. N Engl J Med. 2003;348(7):593-600. https://doi.org/10.1 056/NEJMoa022287.

9. Werner N, Kosiol S, Schiegl T, Ahlers P, Walenta K, Link A, et al. Circulating endothelial progenitor cells and cardiovascular outcomes. N Engl J Med. 2005;353(10):999-1007. https://doi.org/10.1056/NEJMoa043814.

10. Ding $Y$, Sun X, Shan PF. MicroRNAs and cardiovascular disease in diabetes mellitus. Biomed Res Int. 2017;2017:4080364-8. https://doi.org/10.1155/201 $7 / 4080364$.

11. Ray SL, Coulson DJ, Yeoh MLY, Tamara A, Latief JS, Bakhashab S et al. The role of miR-342 in vascular health. Study in subclinical cardiovascular disease in mononuclear cells, plasma, inflammatory cytokines and PANX2. Int J Mol Sci. 2020;21(19). doi:https://doi.org/10.3390/ijms21197217.

12. Urbich C, Kuehbacher A, Dimmeler S. Role of microRNAs in vascular diseases, inflammation, and angiogenesis. Cardiovasc Res. 2008;79(4):581-8. https://doi.org/10.1093/cvr/cvn156.

13. Barwari T, Joshi A, Mayr M. MicroRNAs in cardiovascular disease. J Am Coll Cardiol. 2016;68(23):2577-84. https://doi.org/10.1016/j.jacc.2016.09.945.

14. Zhou SS, Jin JP, Wang JQ, Zhang ZG, Freedman JH, Zheng Y, et al. miRNAS in cardiovascular diseases: potential biomarkers, therapeutic targets and challenges. Acta Pharmacol Sin. 2018;39(7):1073-84. https://doi.org/10.103 8/aps.2018.30

15. Andreou I, Sun X, Stone PH, Edelman ER, Feinberg MW. miRNAs in atherosclerotic plaque initiation, progression, and rupture. Trends Mol Med. 2015;21(5):307-18. https://doi.org/10.1016/j.molmed.2015.02.003.

16. Aquila $G$, Fortini $C$, Pannuti $A$, Delbue $S$, Pannella M, Morelli MB, et al. Distinct gene expression profiles associated with Notch ligands Delta-like 4 and Jagged 1 in plaque material from peripheral artery disease patients: a pilot study. J Transl Med. 2017;15(1):98. https://doi.org/10.1186/s12967-01 7-1199-3.

17. Kim J, Kang Y, Kojima Y, Lighthouse JK, Hu X, Aldred MA, et al. An endothelial apelin-FGF link mediated by miR-424 and miR-503 is disrupted in pulmonary arterial hypertension. Nat Med. 2013;19(1):74-82. https://doi. org/10.1038/nm.3040.

18. Starikova I, Jamaly S, Sorrentino A, Blondal T, Latysheva N, Sovershaev M, et al. Differential expression of plasma miRNAs in patients with unprovoked venous thromboembolism and healthy control individuals. Thromb Res. 2015;136(3):566-72. https://doi.org/10.1016/j.thromres.2015.07.005.

19. Wang $X$, Sundquist K, Elf JL, Strandberg K, Svensson PJ, Hedelius A, et al. Diagnostic potential of plasma microRNA signatures in patients with deepvein thrombosis. Thromb Haemost. 2016;116(2):328-36. https://doi.org/10.11 60/TH16-01-0071.

20. Snowhite IV, Allende G, Sosenko J, Pastori RL, Messinger Cayetano S, Pugliese A. Association of serum microRNAs with islet autoimmunity, disease progression and metabolic impairment in relatives at risk of type 1 diabetes. Diabetologia. 2017;60(8):1409-22. https://doi.org/10.1007/s00125017-4294-3

21. Choi YE, Cha YR, Lee KM, Kim HJ, Yoon CH. Proangiogenic cells enhanced persistent and physiologic neovascularization compared with macrophages. Exp Mol Med. 2015;47(9):e186. https://doi.org/10.1038/emm.2015.60.

22. Tepper OM, Galiano RD, Capla JM, Kalka C, Gagne PJ, Jacobowitz GR, et al. Human endothelial progenitor cells from type II diabetics exhibit impaired proliferation, adhesion, and incorporation into vascular structures. Circulation. 2002;106(22):2781-6. https:/doi.org/10.1161/01.cir.0000039526.42991.93.

23. Huang $\mathrm{PH}$, Chen $\mathrm{YH}$, Chen YL, Wu TC, Chen JW, Lin SJ. Vascular endothelial function and circulating endothelial progenitor cells in patients with cardiac syndrome X. Heart. 2007;93(9):1064-70. https://doi.org/10.1136/hrt.2006.1 07763.

24. Karagkouni D, Paraskevopoulou MD, Chatzopoulos S, Vlachos IS, Tastsoglou S, Kanellos I, et al. DIANA-TarBase v8: a decade-long collection of experimentally supported miRNA-gene interactions. Nucleic Acids Res. 2018; 46(D1):D239-D45. https://doi.org/10.1093/nar/gkx1141.
25. Alnek K, Kisand K, Heilman K, Peet A, Varik K, Uibo R. Increased blood levels of growth factors, proinflammatory cytokines, and Th17 cytokines in patients with newly diagnosed type 1 diabetes. PLoS One. 2015;10(12): e0142976. https://doi.org/10.1371/journal.pone.0142976.

26. Bakhashab S, Ahmed F, Schulten HJ, Ahmed FW, Glanville M, Al-Qahtani $\mathrm{MH}$, et al. Proangiogenic effect of metformin in endothelial cells is via upregulation of VEGFR1/2 and their signaling under hyperglycemia-hypoxia. Int J Mol Sci. 2018;19(1). doi:https://doi.org/10.3390/ijms19010293.

27. Sasso FC, Torella D, Carbonara O, Ellison GM, Torella M, Scardone M, et al. Increased vascular endothelial growth factor expression but impaired vascular endothelial growth factor receptor signaling in the myocardium of type 2 diabetic patients with chronic coronary heart disease. J Am Coll Cardiol. 2005;46(5):827-34. https://doi.org/10.1016/j.jacc.2005.06.007.

28. Waltenberger J, Lange J, Kranz A. Vascular endothelial growth factor-Ainduced chemotaxis of monocytes is attenuated in patients with diabetes mellitus: a potential predictor for the individual capacity to develop collaterals. Circulation. 2000;102(2):185-90. https://doi.org/10.1161/01.cir.1 02.2.185.

29. Calzascia T, Pellegrini M, Lin A, Garza KM, Elford AR, Shahinian A, et al. CD4 $T$ cells, lymphopenia, and IL-7 in a multistep pathway to autoimmunity. Proc Natl Acad Sci U S A. 2008;105(8):2999-3004. https://doi.org/10.1073/ pnas.0712135105.

30. Osawa Y, Nagaki M, Banno Y, Brenner DA, Asano T, Nozawa Y, et al. Tumor necrosis factor alpha-induced interleukin-8 production via NF-kappaB and phosphatidylinositol 3-kinase/Akt pathways inhibits cell apoptosis in human hepatocytes. Infect Immun. 2002;70(11):6294-301. https://doi.org/10.1128/iai. 70.11.6294-6301.2002.

31. Emadi S, Clay D, Desterke C, Guerton B, Maquarre E, Charpentier A, et al. IL8 and its CXCR1 and CXCR2 receptors participate in the control of megakaryocytic proliferation, differentiation, and ploidy in myeloid metaplasia with myelofibrosis. Blood. 2005;105(2):464-73. https://doi.org/1 0.1182/blood-2003-12-4415.

32. Golia E, Limongelli G, Natale F, Fimiani F, Maddaloni V, Pariggiano I, et al. Inflammation and cardiovascular disease: from pathogenesis to therapeutic target. Curr Atheroscler Rep. 2014;16(9):435. https://doi.org/10.1007/s11883-014-0435-z.

33. King TF, McDermott JH. Endothelial progenitor cells and cardiovascular disease. J Stem Cells. 2014;9(2):93-106 doi:jsc.2014.9.2.93.

34. Peng HY, Jiang SS, Hsiao JR, Hsiao M, Hsu YM, Wu GH, et al. IL-8 induces miR-424-5p expression and modulates SOCS2/STAT5 signaling pathway in oral squamous cell carcinoma. Mol Oncol. 2016;10(6):895-909. https://doi. org/10.1016/j.molonc.2016.03.001.

35. Baggiolini M, Dewald B, Moser B. Interleukin-8 and related chemotactic cytokines--CXC and CC chemokines. Adv Immunol. 1994;55:97-179.

36. Olson TS, Ley K. Chemokines and chemokine receptors in leukocyte trafficking. Am J Physiol Regul Integr Comp Physiol. 2002;283(1):R7-28. https://doi.org/10.1152/ajpregu.00738.2001.

37. Yue $T L$, Wang $X$, Sung CP, Olson B, McKenna PJ, Gu JL, et al. Interleukin-8. A mitogen and chemoattractant for vascular smooth muscle cells. Circ Res. 1994;75(1):1-7. https://doi.org/10.1161/01.res.75.1.1.

38. Damas JK, Waehre T, Yndestad A, Otterdal K, Hognestad A, Solum NO, et al. Interleukin-7-mediated inflammation in unstable angina: possible role of chemokines and platelets. Circulation. 2003;107(21):2670-6. https://doi.org/1 0.1161/01.CIR.0000070542.18001.87

39. Prondzinsky R, Unverzagt S, Lemm H, Wegener NA, Schlitt A, Heinroth KM, et al. Interleukin-6, $-7,-8$ and -10 predict outcome in acute myocardial infarction complicated by cardiogenic shock. Clin Res Cardiol. 2012;101(5): 375-84. https://doi.org/10.1007/s00392-011-0403-3.

40. Li R, Paul A, Ko KW, Sheldon M, Rich BE, Terashima T, et al. Interleukin-7 induces recruitment of monocytes/macrophages to endothelium. Eur Heart J. 2012;33(24):3114-23. https://doi.org/10.1093/eurheartj/ehr245.

41. Mihailovic PM, Lio WM, Yano J, Zhou J, Zhao X, Chyu KY, et al. IL-7R blockade reduces post-myocardial infarction-induced atherosclerotic plaque inflammation in ApoE(-/-) mice. Biochem Biophys Rep. 2019;19:100647. https://doi.org/10.1016/j.bbrep.2019.100647.

42. Su T, Gu C, Draga D, Zhou C, Lhamo T, Zheng Z, et al. Integrative analysis of miRNA-mRNA network in high altitude retinopathy by bioinformatics analysis. Biosci Rep. 2021;41(1). doi:https://doi.org/10.1042/BSR20200776.

43. Binderup HG, Madsen JS, Heegaard NHH, Houlind K, Andersen RF, Brasen CL. Quantification of microRNA levels in plasma - impact of preanalytical and analytical conditions. PLoS One. 2018;13(7):e0201069. https://doi.org/1 0.1371/journal.pone.0201069. 
44. Wang G, Yan Y, Zheng Z, Zhang T. The mechanism of hsa-miR-424-5 combining PD-1 through mTORC signaling pathway to stimulate immune effect and participate in type 1 diabetes. Biosci Rep. 2020;40(3). doi:https:// doi.org/10.1042/BSR20193800.

45. Kong Q, Guo X, Guo Z, Su T. Urinary exosome miR-424 and miR-218 as biomarkers for type 1 diabetes in children. Clin Lab. 2019;65(6). doi:https:// doi.org/10.7754/Clin.Lab.2018.180921.

46. Lang H, Xiang $Y$, Lin N, Ai Z, You Z, Xiao J, et al. Identification of a panel of MiRNAs as positive regulators of insulin release in pancreatic beta-cells. Cell Physiol Biochem. 2018;48(1):185-93. https://doi.org/10.1159/000491717.

47. Liu SP, Fu YF, Huang R, Gao M, Gui R, Qu Y, et al. MicroRNA-424 overexpression attenuates high glucose and inflammation suppressed osteogenic differentiation. Int J Clin Exp Med. 2016;9(10):20118-25.

48. Colagiuri S, Lee CM, Wong TY, Balkau B, Shaw JE, Borch-Johnsen K, et al. Glycemic thresholds for diabetes-specific retinopathy: implications for diagnostic criteria for diabetes. Diabetes Care. 2011;34(1):145-50. https://doi. org/10.2337/dc10-1206.

49. Expert Committee on the D, Classification of Diabetes M. Report of the expert committee on the diagnosis and classification of diabetes mellitus. Diabetes Care. 2003;26(Suppl 1):S5-20. https://doi.org/10.2337/diacare.26.2 007.s5.

50. Zhao M, Xu L, Qian H. Bioinformatics analysis of microRNA profiles and identification of microRNA-mRNA network and biological markers in intracranial aneurysm. Medicine (Baltimore). 2020;99(31):e21186. https://doi. org/10.1097/MD.0000000000021186.

51. Bye A, Rosjo H, Nauman J, Silva GJ, Follestad T, Omland T, et al. Circulating microRNAs predict future fatal myocardial infarction in healthy individuals the HUNT study. J Mol Cell Cardiol. 2016;97:162-8. https://doi.org/10.1016/j. yjmcc.2016.05.009.

52. Chamorro-Jorganes A, Araldi E, Penalva LO, Sandhu D, Fernandez-Hernando C, Suarez Y. MicroRNA-16 and microRNA-424 regulate cell-autonomous angiogenic functions in endothelial cells via targeting vascular endothelial growth factor receptor-2 and fibroblast growth factor receptor-1. Arterioscler Thromb Vasc Biol. 2011;31(11):2595-606. https://doi.org/10.11 61/ATVBAHA.111.236521.

53. Rosano S, Cora D, Parab S, Zaffuto S, Isella C, Porporato $R$, et al. A regulatory microRNA network controls endothelial cell phenotypic switch during sprouting angiogenesis. Elife. 2020;9. https://doi.org/10.7554/eLife.48095.

\section{Publisher's Note}

Springer Nature remains neutral with regard to jurisdictional claims in published maps and institutional affiliations.

Ready to submit your research? Choose BMC and benefit from:

- fast, convenient online submission

- thorough peer review by experienced researchers in your field

- rapid publication on acceptance

- support for research data, including large and complex data types

- gold Open Access which fosters wider collaboration and increased citations

- maximum visibility for your research: over $100 \mathrm{M}$ website views per year

At $\mathrm{BMC}$, research is always in progress.

Learn more biomedcentral.com/submissions 